\title{
O PÓS-DOUTORADO NO CONTEXTO DO SISTEMA DE PÓS- GRADUAÇÃO NO BRASIL
}

\author{
Marcelo Labanca Corrêa de Araújo ${ }^{1}$
}

\section{Colocação do tema}

O presente trabalho enfrenta o tema da figura do pós-doutorado para situálo no contexto do sistema de pós-graduação no Brasil, notadamente investigando sua relevância e seu impacto na formação de pesquisadores e seus reflexos para a formação de mestres e doutores.

Há diversos tratamentos existentes para o pós-doutorado, também chamado de estágio pós-doutoral. A depender da agência de fomento, da universidade ou do país, o tema pode receber um regramento específico. A ausência de uniformidade de tratamento desse tema gera uma série de dúvidas sobre o que é, efetivamente, um pós-doutorado.

Questionamentos devem ser enfrentados como, por exemplo, se o pósdoutorado é um título acadêmico; se há um tempo máximo ou mínimo; se há defesa de tese de pós-doutorado; se há um orientador ou um supervisor da pesquisa e quais as diferenças de papéis entre essas duas figuras; como se dá o acesso a bolsas de pósdoutorado; se é um curso com disciplinas; qual impacto que o pós-doutorado gera no sistema de pós-graduação, notadamente no que diz respeito à internacionalização e ao aumento da produção científica; e, por fim, quais são os requisitos para a realização de um pós-doutorado por parte do pesquisador brasileiro ou, ainda, os requisitos para a oferta de um pós-doutorado por parte de uma universidade brasileira. A quantidade de pesquisadores com pós-doutorado auxiliou positivamente a produção da pesquisa no âmbito da pós-graduação stricto sensu, bem como houve também benefícios para o ensino e a extensão?

Essas perguntas serão respondidas a partir de uma pesquisa que busca evidenciar a realidade jurídico-normativa do pós-doutorado no Brasil, tomando como base a investigação de regras de diversas ordens sobre o tema (tanto de órgãos de fomento quanto de universidades) e, também, a realidade concreta dos impactos do pós-doutorado para o fortalecimento do sistema de pós-graduação stricto sensu (mestrados e doutorados).

Mestre e doutor em Direito (UFPE), tendo realizado pós-doutorado na Universidade de Pisa, Itália, pelo Programa de Estágio Pós-Doutoral no Exterior, da Capes. Professor permanente do mestrado e doutorado da Universidade Católica de Pernambuco. 
2. Pós-doutorado e pós-graduação: entre consensos e dissensos

De chofre, é importante esclarecer que não há uma regra geral definindo o que é um pós-doutorado que seja aplicável a todas as instituições. O que existe são diversos regulamentos esparsos das mais diversas agências de fomento, cada uma estabelecendo critérios para ingresso em programas de estágio pós-doutoral, que nada mais é do que um período em que o docente ou pesquisador executará uma pesquisa em uma instituição chamada de receptora. Há, também, os regulamentos criados pelas próprias instituições receptoras para aceitar um profissional externo para a execução de determinada pesquisa proposta.

Apesar da multiplicidade de normas aplicáveis, há um consenso indicando que o pós-doutorado não é um curso integrante do sistema de pós-graduação no Brasil. Não está contemplado como um curso nos moldes, por exemplo, de um doutorado.

A pós-graduação stricto sensu, para além das especializações, é constituída pelos cursos de mestrado e doutorado, com carga horária de aulas, pesquisa e orientação para, ao final, ocorrer a defesa de dissertação ou tese perante uma banca examinadora. Com isso, obtém-se o de título de mestre ou de doutor. Já o pós-doutorado não é uma pós-graduação, mas, sim, um estágio de pesquisa e, por isso, "não se trata de curso de formação, e sim de reciclagem e atualização de pesquisadores já formados". ${ }^{2}$

Há diversas diferenças entre a pós-graduação e o pós-doutorado. A lógica do pós-doutorado é de troca. Enquanto em um mestrado ou doutorado (cursos) o aluno ainda está "recebendo" informações para a construção de sua formação acadêmica, no pós-doutorado (pesquisa) ele já assume um papel de "entrega", já que passa a colaborar com a instituição ao qual estará vinculado durante o desenvolvimento de seu estágio de pesquisa. ${ }^{3} \mathrm{O}$ pesquisador que desenvolve uma pesquisa pós-doutoral não cursa disciplinas e não é considerado um aluno na instituição que o recebe. Ao contrário, possui sua formação completa (pois já é doutor), podendo, inclusive, ministrar aulas, seminários e conferências, a depender das regras da instituição onde desenvolve sua pesquisa.

Mesmo não sendo o pós-doutorado integrante do sistema de pósgraduação, ${ }^{4}$ há uma forte ligação com ele. A Capes (Coordenação de Aperfeiçoamento

2 CARAIOLA, Diego Maganhotto et al. Pós-Doutorado na Formação dos Docentes de Programas de PósGraduação em Administração no Brasil - Perfil e Configuração. In: III Encontro de Ensino e Pesquisa em Administração e Contabilidade. João Pessoa, 20 a 22 de novembro de 2011. Disponível em: http://www. anpad.org.br/admin/pdf/EnEPQ435.pdf. Acesso em: 28 jan. 2021.

3 “inúmeras são as expectativas geradas em relação ao profissional que realiza este tipo de atualização e reciclagem, principalmente no que se refere à contribuição que ele poderá dar ao programa que esteja vinculado". CARAIOLA, cit., p. 2.

4 O doutorado, e não o pós-doutorado, é o mais alto grau acadêmico de formação. Essa é a orientação também presente na tradicional Universidade de Bologna: "Il dottorato di ricerca è il più alto grado di istruzione previsto nell>ordinamento accademico italiano". Disponível em: https:/www.unibo.it/it/ 
de Pessoal de Nível Superior), na qualidade de órgão central de fomento, regulação e avaliação do sistema de pós-graduação stricto sensu, destina uma parte de seu orçamento para pesquisas de pós-doutorado mediante concessão de bolsas de estágio pós-doutoral dentro dos programas de pós-graduação nacionais e, também, mediante concessão direta de bolsas de pós-doutorado para serem executadas no exterior. Para além do mero financiamento, no quesito avaliação da pós-graduação, um programa é avaliado positivamente se possui, em seu quadro, professores permanentes que demonstrem terem realizado estágios pós-doutorais, notadamente se tiverem sido no exterior. É um item que ajuda a uma melhor avaliação do programa. Isso faz com que o pós-doutorado, embora não seja algo integrante do sistema de pós-graduação, tenha uma proximidade íntima com os programas de mestrado e doutorado.

Naturalmente, há outros aspectos que demonstram as diferenças entre o pós-doutorado e uma pós-graduação. Por exemplo, no pós-doutorado, não se exige um orientador (como em um mestrado ou doutorado) mas, no máximo, um supervisor de pesquisa. O processo de orientação de uma tese de doutorado permite que o orientador exerça um papel relevante no desenvolvimento da dissertação de mestrado ou da tese de doutorado (do início ao fim, desde a escolha do tema até a defesa perante a banca). Já no pós-doutorado, é designado um professor da instituição receptora para exercer o papel de supervisor da pesquisa, porém sem controle de mérito ou ingerência quanto ao tema ou ao percurso metodológico.

O pós-doutorado é um estágio de pesquisa normalmente realizado por "jovens doutores" em alguma instituição receptora (predominantemente programas de pós-graduação, mas não apenas). O termo “jovem” não diz respeito à idade, por óbvio, e sim ao tempo passado em relação à data de defesa da tese de doutorado. Explico: é comum aos editais de agências de fomento estabelecer um tempo máximo após a defesa de doutorado como critério para a obtenção de bolsa. Veja-se o caso da Fundação de Amparo à Pesquisa do Estado de São Paulo (Fapesp):

A bolsa de Pós-Doutorado da Fapesp tem por objetivo criar condições para a incorporação temporária a grupos de pesquisa ativos no Estado de São Paulo de cientistas muito promissores, que tenham obtido o título de doutor há menos de 7 (sete) anos, no país ou no exterior, com destacado desempenho, para contribuírem ao desenvolvimento de pesquisa em Instituição localizada no Estado de São Paulo. ${ }^{5}$ 
Do que consta nas regras para a obtenção de bolsas pela agência de fomento à pesquisa do Estado de São Paulo, é possível observar que o pós-doutorado, como já afirmado anteriormente, não é algo apenas benéfico ao pesquisador que recebe ensinamentos, mas, sobretudo, é benéfico à instituição receptora, em função da troca de conhecimentos proporcionada pelo período de estágio. É um reforço que a instituição receptora ganha, acrescentando mais um pesquisador ao seu time. Também, da regra mencionada, é possível observar uma limitação temporal considerando a data de defesa da tese de doutorado. No caso da Fapesp, essa limitação é de sete anos. Essas regras podem variar de agência para agência. Mas é uma constante o fato de que o pós-doutorado é algo desenvolvido por jovens doutores. A Capes, por exemplo, firma parcerias com instituições estrangeiras para a concessão de bolsas, como é o caso das conhecidas bolsas Fulbright, ${ }^{6}$ nos Estados Unidos, ou Iiasa, ${ }^{7}$ na Áustria, que estipulam o prazo não maior que oito anos após a defesa da tese como requisito para a inscrição no processo seletivo. Vejam que não estou falando de inscrição perante a instituição estrangeira, mas, sim, perante a própria Capes, para fins de obtenção da bolsa. Assim, o candidato deve atuar em dois fronts: obter o acesso junto à instituição estrangeira e apresentar a carta de aceite perante a Capes para poder participar do processo seletivo de bolsa de pós-doutorado.

Como se vê, no quesito "jovens doutores” não há uma definição jurídiconormativa de quanto tempo isso represente. Há editais prevendo tempos diversos após a defesa do doutorado para que o candidato possa desenvolver seu pós-doutorado com financiamento. Mas é consenso de que o pós-doutorado se aplica a doutores recentes. A própria Capes alterou a sua regulamentação para criar a figura da bolsa de Estágio Sênior. ${ }^{8}$ Isso foi uma forma de evitar que o professor brasileiro experiente fosse ao exterior com uma bolsa de pós-doutorado (algo que é tipicamente aplicável a professores recentes no início de carreira). A criação da figura do Estágio Sênior resolveu isso. ${ }^{9}$

6 Disponível em: https://fulbright.org.br/wp-content/uploads/2015/06/1662014-034-2014-Fulbright-POSDOC-1.pdf. Acesso em: 5 fev. 2021.

7 Disponível em: http://www1.capes.gov.br/36-noticias/10142-editais-oferecem-bolsas-de-doutorado-epos-doutorado-na-austria. Acesso em: 5 fev. 2021.

8 "A partir de 2009, o programa da Capes de estágio pós-doutoral foi desmembrado em dois subprogramas: um voltado para o público em geral e outro para doutores com elevada produtividade científica. Em 2012, o programa foi novamente reformulado buscando atender a dois perfis acadêmicos diferenciados: os doutores com menos de 8 anos de titulação (recém-doutores e os intermediários na carreira acadêmica) e os com 8 anos ou mais de titulação (pesquisadores sêniores)". CASTRO, Pedro Marcos Roma de. Impacto dos Estágios Pós-Doutorais no Exterior: a influência além da produção científica no sistema de pósgraduação. Tese de Doutorado, Departamento de Administração, Faculdade de Economia, Administração e Contabilidade, USP. São Paulo, 2013, p. 22.

$9 \quad$ Usando a técnica do storytelling, posso aqui abrir parênteses para relatar minha experiência pessoal: morei um ano na Itália, na qualidade de bolsista do programa de estágio pós-doutoral no exterior da Capes, desenvolvendo minha pesquisa junto à Faculdade de Direito da Universidade de Pisa, Toscana. Todavia, apesar de ser apresentado, pelos documentos oficiais da Capes, como pesquisador de pós-doutorado, eu já era professor permanente do Programa de Pós-Graduação da Universidade Católica de Pernambuco. 
Posteriormente, a própria Capes determinou que o Programa de Estágio Sênior no Exterior passasse a se chamar, a partir de 2018, Programa Professor Visitante no Exterior - Sênior. ${ }^{10}$ Assim, se antes de 2009 um professor experiente fosse realizar uma pesquisa no exterior, ele poderia ir amparado com uma bolsa de pós-doutorado. Hoje, ele vai como bolsista do programa de professor visitante. Mais uma vez, a Capes, órgão regulador do sistema de pós-graduação, tenta simetrizar as expressões utilizadas no Brasil para que sejam compatíveis com o uso que lhes é dado no exterior. Lá fora, pós-doutorado é um estágio de pesquisa desenvolvido por um jovem doutor.

Então, pode-se dizer que as expressões "estágio de pós-doutorado", "estágio sênior" ou "professor visitante" (os chamados visitings nos EUA) possuem a mesma base: o desenvolvimento de uma pesquisa em uma instituição receptora após a realização da defesa da tese de doutorado. Mas, se o pesquisador é um jovem doutor, será considerado então um pós-doutorado. Se, por outro lado, já for um pesquisador experiente, será considerado integrante de um estágio sênior ou professor visitante.

\section{O pós-doutorado gera um título a mais na carreira acadêmica?}

Considerando clara a diferença entre pós-graduação e pós-doutorado, pode-se afirmar, sem medo de dúvidas, que não é adequado chamar de pós-doutor alguém que tenha realizado uma pesquisa de pós-doutorado. Enquanto quem faz um doutorado pode ser chamado de doutor, quem faz o pós-doutorado não pode ser chamado de pós-doutor por uma simples razão: no primeiro caso (doutorado), temos uma etapa de formação pessoal acadêmica com a obtenção de um título. Estamos falando da pessoa, do profissional docente ou pesquisador que obtém um grau acadêmico. No segundo caso (pós-doutorado), não estamos falando da pessoa que realiza um curso para obter um grau acadêmico, e sim de uma pesquisa que está sendo realizada: a pesquisa de pósdoutorado. Uma coisa é a pessoa. Outra, a pesquisa. Com isso, pode-se dizer que há pósdoutorado, mas não há pós-doutor. Há, todavia, quem discorde e utilize a nomenclatura "pós-doutor" para designar aquele que terminou um pós-doutorado. ${ }^{11}$ A Universidade de

Na Universidade de Pisa, eles não me consideravam como Professore Ospite e me davam tratamento diferente (inclusive em acomodações) dos demais pesquisadores que realizavam um post dottorato, todos eles jovens doutores em início de carreira e ainda não empregados em universidades. Percebi que o pósdoutorado na Itália funciona, então, como forma de manter o recém-doutor pesquisando enquanto ele não consegue passar em algum concurso docente. Fui vendo, aos poucos, que a expressão "pós-doutorado" no Brasil não possuía o mesmo significado na Europa.

10 Disponível em: https://www1.capes.gov.br/bolsas-e-auxilios-internacionais/pais/218-multinacional/9085programa-de-estagio-senior-no-exterior-desativado. Acesso em: 3 fev. 2021.

11 É o caso de Valério Mazzuoli, como aqui pode ser visto em: http://genjuridico.com.br/2020/08/06/oque-e-um-pos-doutorado/. Acesso em: 3 fev. 2021. Segundo Mazzuoli, "não obstante não existir um 'título' de Pós-Doutor, nada impede - ao contrário, incentiva-se - que se nomine pós-doutor aqueles que concluíram com êxito um estágio de pós-doutoramento. Não se atribui, pela nomenclatura utilizada, 
São Paulo (USP), em seu regulamento do programa de Pós-Doutorado, utiliza, inclusive, a expressão "pós-doutorando" para designar os pesquisadores integrantes daquele programa. ${ }^{12}$ No meu sentir, sem razão.

O próprio sistema do currículo Lattes faz uma distinção. Ao alimentar o sistema, existe o campo para "formação acadêmica/titulação" com os seguintes níveis: ensino fundamental, ensino médio, ensino profissional de nível técnico, graduação, mestrado ou doutorado. São etapas da formação acadêmica onde a pessoa obtém graus que correspondem a títulos. O sistema do currículo Lattes não apresenta, nesse campo, espaço para inserir o pós-doutorado. Ao contrário, cria um campo específico intitulado "pós-doutorado e/ou livre docência", apartando esses conceitos daqueles outros correspondentes à formação acadêmica com obtenção de título.

Assim, no âmbito da pós-graduação stricto sensu, ou você é mestre ou é doutor. É possível ao professor ou pesquisador falar que realizou pós-doutorado. Mas não que é pós-doutor, justamente porque não é uma qualificação do pesquisador, mas, sim, da pesquisa.

4. Existe defesa de pós-doutorado perante uma banca?

Outra questão que deve ser enfrentada diz respeito ao resultado do pósdoutorado e se pode, ou não, ser nominado de tese com defesa perante uma banca.

Nesse caso, diante da ausência de uma regulamentação nacional, a questão é muito dependente do que solicita a agência de fomento que concede a bolsa para a pesquisa de pós-doutorado. Também pode variar em razão das normas internas de cada instituição receptora. Vamos exemplificar.

Se o pesquisador obtém uma bolsa de pós-doutorado pelo PNPD (Programa Nacional de Pós-Doutorado), da Capes, o art. $6^{\circ}$ do regulamento exige do bolsista "elaborar Relatório de Atividades Anual a ser submetido à aprovação do

qualquer título acadêmico a um Doutor, para além do seu próprio doutorado, senão apenas se identifica o docente-pesquisador que realizou/concluiu estágio de pós-doutoramento em uma Universidade (nacional ou estrangeira) detentora de um programa de Pós-Doutoramento. Não há nada de estranho ou anormal, portanto, em alguém se dizer Mestre, Doutor e Pós-Doutor se concluiu um mestrado, um doutorado e um pós-doutorado na vida acadêmica, independentemente desta última etapa ser apenas um estágio de pesquisa e não um título acadêmico." Com a devida vênia, se o próprio autor reconhece as diferenças entre pós-graduação e pós-doutorado e que este último não concede um título acadêmico a quem o executa, me parece desarrazoado sustentar ser possível designar alguém de pós-doutor pelo fato de ele ter executado a pesquisa. Afinal, a qualificação não recai na pessoa como grau acadêmico, mas, sim, recai sobre a pesquisa executada.

12 Resolução CoPq n. 7660, de 22 de maio de 2019. Disponível em: http://www.leginf.usp. br/?resolucao=resolucao-copq-no-7660-de-22-de-maio-de-2019. Acesso em: 29 jan. 2021. 
Programa de Pós-Graduação e encaminhar Relatório Final em até 60 (sessenta) dias após o encerramento da respectiva bolsa" ${ }^{13}$

Observem que a expressão utilizada pelo normativo não é tese. Portanto, não há "tese de pós-doutorado", a não ser que se utilize a linguagem coloquial para a expressão. Sendo o pós-doutorado nada mais que um estágio de pesquisa, o que se espera é a apresentação de um relatório da pesquisa executada.

Outra questão que chama a atenção na norma indicada é a "aprovação do Programa de Pós-Graduação". Nessa parte, a norma estabelece a aprovação de relatórios anuais. Já quanto ao relatório final, exige-se apenas o envio à Capes.

É importante dizer que os programas são autônomos para disciplinarem em seus respectivos colegiados como será essa etapa de chancela. Assim, nada impede que programas prevejam a apresentação pública perante banca do relatório de pesquisa. É até salutar, para dar visibilidade ao que vem sendo feito pelos pesquisadores e compartilhar com a comunidade os resultados da pesquisa. Pode, também, haver a aprovação em via escrita, submetida ao colegiado ou, ainda, delegação da aprovação a comissões especificamente criadas para isso.

Enfim, diante da ausência de regra da Capes que indique a necessidade de defesa perante uma banca, a instituição receptora tem autonomia para disciplinar internamente as regras de pós-doutorado. Atender às exigências do órgão de fomento pode não ser, portanto, suficiente. Ficar atento às regras da própria universidade é um imperativo para que a pesquisa de pós-doutorado seja concluída com êxito.

A Pró-Reitoria de Pesquisa da Universidade de São Paulo, por exemplo, disciplina o procedimento determinando a entrega de relatório pelo sistema Atena em até 60 dias do prazo, sob pena de não emissão de atestado. Vejam a expressão: atestado. $^{14}$ Não há diploma ou ata de defesa.

De toda sorte, dar visibilidade à pesquisa realizada é mais do que salutar no mundo científico. Por isso, é muito comum que pesquisadores busquem algum periódico bem avaliado e com boa circulação para ser veículo de publicação da pesquisa de pósdoutorado. Se sujeitar às críticas da comunidade científica quanto ao resultado produzido retrata a postura aberta que gera a evolução científica. ${ }^{15}$

13 Ver em https://www.gov.br/capes/pt-br/centrais-de-conteudo/portaria-86-2013-regulamento-pnpd-pdf. Acesso em: 5 fev. 2021.

14 Art. $7^{\circ}$ da Resolução CoPq n. 7406, de 3 de outubro de 2017, alterada pela Resolução CoPq n. 7.660.

15 Para Popper, a refutabilidade de um postulado se constitui na própria essência da natureza científica. Assim, para não cair na armadilha do Rei Filósofo, que impõe um fechamento com base na sua soberania, "o apelo de Popper, ao longo do segundo volume da Sociedade Aberta e seus inimigos, consiste em chamar a atenção para a necessidade de que as teorias sejam suscetíveis à refutação, porque são falíveis". SILVA, Robert Brenner Barreto da. Falibilidade Do Conhecimento: Reflexões Sobre a Abertura da Ciência e da Sociedade na Filosofia de Karl Popper. In: Revista Seara Filosófica, Número 18, 2019, p. 59 (p. 49-61). 
5. O tempo de duração de um pós-doutorado

Questão curiosa é saber se há um prazo mínimo ou máximo para que o pós-doutorado seja realizado. Como temos afirmado durante essa investigação, não há uma norma central disciplinando as regras para oferta ou execução de um pós-doutorado, justamente porque não se trata de um curso (normalmente os cursos são regulamentados). Não há um prazo específico e rígido. Depende do grau de complexidade da pesquisa que será executada. A USP estabelece um prazo em horas: 960 horas. ${ }^{16}$ Algumas bolsas de fomento indicam um mínimo de 6 meses ou um máximo de 24 meses quando para o exterior. No Brasil, as bolsas de pós-doutorado que são distribuídas pelos programas de pós-graduação stricto sensu (as chamadas bolsas PNPD, que explicaremos a seguir) podem ter como prazo máximo 60 meses.

Diante da ausência de regra geral estipulando prazo para o desenvolvimento da pesquisa, o que se demonstra é a necessidade de o tempo ser compatível com a execução da pesquisa proposta.

Ao fim e a cabo, o que vai nortear o prazo mínimo são as regras da entidade financiadora ou da instituição receptora que pode estipular um tempo de execução que, sem cumpri-lo, não seria possível atribuir um atestado de finalização do estágio pósdoutoral.

6. Bolsas de pós-doutorado dentro e fora do sistema de pós-graduação stricto sensu

Os programas de pós-graduação stricto sensu recebem da Capes diversos tipos de bolsas para distribuírem internamente, como, por exemplo, as conhecidas bolsas de mestrado e doutorado. Nesse caso, o bolsista não necessita fazer uma solicitação à Capes. Todo o requerimento e o processo seletivo é desenvolvido internamente, pelo programa, que possui autonomia de decidir para quem destinará a bolsa. O PPG protagoniza o acesso e o recrutamento.

Assim, exemplificando, determinado programa pode ter uma cota de vinte bolsas de doutorado. Na medida em que um doutorando bolsista defende sua tese, o próprio programa pode remanejar a bolsa vacante para outro doutorando não bolsista. Então, o que quero enfatizar é a autonomia do programa em decidir quem obterá a bolsa. Há balizas gerais que fazem parte da regulamentação da Capes para essas bolsas, como, por exemplo, a necessidade de criação de uma comissão de seleção da qual o coordenador deve participar, presidindo-a. Mas a autonomia para a concessão (ou não concessão) é uma decisão do próprio programa, não do órgão de fomento.

16 https://prp.usp.br/wp-content/uploads/sites/649/2016/05/Guia-para-o-Programa-de-P\%C3\%B3sDoutorado-da-USP.pdf. 
Se isso ocorre com bolsas de mestrado e doutorado, também ocorre com bolsas de pós-doutorado por meio do chamado PNPD (Programa Nacional de Pós-Doutorado). ${ }^{17}$ Ou seja, os programas acadêmicos de pós-graduação stricto sensu recebem da Capes uma cota específica de bolsas de pós-doutorado para que procedam ao recrutamento de pesquisadores nacionais ou estrangeiros interessados em desenvolver alguma pesquisa dentro do programa.

Os diversos programas podem utilizar essas bolsas estabelecendo condições que atendam às necessidades ou especificidades de suas linhas de pesquisa. A autonomia, nesse caso, não é da universidade, mas do próprio programa. Portanto, considerem que um PPG em Farmácia pode estabelecer um processo seletivo para conceder suas bolsas de pós-doutorado com critérios diferentes do PPG em Direito. O que normalmente há de comum entre eles é o fato de que os critérios para a concessão terminam sendo construídos internamente para atender às demandas do próprio programa de pós-graduação. Nesse sentido, é inegável reconhecer que o pós-doutorado funciona como uma forma de trazer experts de fora para colaborarem com o programa. Eles concedem bolsas para receber algum pesquisador, seja nacional ou estrangeiro, para que atenda a uma necessidade temática, de internacionalização do programa, de execução de pesquisa empírica, de orientação de mestrandos ou de qualquer outro critério estabelecido no processo seletivo para a concessão da bolsa.

A Universidade de São Paulo, por exemplo, possui uma página própria em seu site para indicar as oportunidades de bolsas de pós-doutorado. O espaço informativo serve para agrupar os editais de bolsas dos mais diversos programas da universidade paulista. ${ }^{18}$ Com uma rápida verificação no site, é possível observar que há editais criados por diversos programas de pós-graduação, com prazos e critérios diferentes entre eles.

Há casos, por outro lado, em que as bolsas não passam por decisão qualquer do programa de pós-graduação. Ou seja, são bolsas que não fazem parte do supramencionado PNPD. Nesse exemplo, encontram-se as bolsas fornecidas por agências de fomento, sejam elas nacionais ou internacionais: privadas, a exemplo da Fundação Ford, da Fundação Carolina e da Fundação Konrad Adenauer-Stiftung; ou públicas, a exemplo das fundações de amparo à ciência dos diversos Estados (como a Fapesp, em São Paulo) e as nacionais, como a Capes e o CNPq.

Nessa hipótese, o candidato deve seguir as regras do edital que normatizam o processo seletivo. O comitê de avaliação para a concessão da bolsa é interno à agência

\footnotetext{
17 "O PNPD/Capes, Programa Nacional de Pós-Doutorado da Capes, é um programa de concessão institucional que financia estágios pós-doutorais em Programas de Pós-Graduação (PPG) stricto sensu acadêmicos recomendados pela Capes". Disponível em: https:/www.gov.br/capes/pt-br/acesso-ainformacao/acoes-e-programas/bolsas/bolsas-no-pais/pnpd-capes. Acesso em: 5 fev. 2021.

18 Disponível em: https://www5.usp.br/tag/pos-doutorado/. Acesso em: 28 jan. 2021.
} 
de fomento (a formação ou composição desse comitê pode contar com agentes externos), e não da própria instituição receptora. A instituição receptora pode, também, criar seu próprio processo seletivo.

Não se pode, naturalmente, estipular aqui quais são as regras para a obtenção dessas bolsas, já que dependerão de cada edital que se traduz na norma regedora do processo seletivo.

\section{Pós-doutorado sem bolsa: é possível?}

Para realizar o pós-doutorado, não é imprescindível se submeter a algum dos processos seletivos mencionados no item anterior (concessão de bolsas em modo direto pelo programa e concessão de bolsa diretamente obtida na agência de fomento). Se o pesquisador deseja realizar alguma pesquisa supervisionada, mas não pretende receber bolsa por qualquer motivo (seja econômico ou de alguma vedação regulamentar), ele pode desenvolvê-la sem participar do processo seletivo elaborado pelo programa de pósgraduação stricto sensu ou por qualquer órgão de fomento, como a Capes, a Fapesp ou o CNPq.

Nesse caso, como funciona? Há alguma regulamentação nacional sobre o assunto? A resposta é negativa. Tudo fica na autonomia da universidade, que pode estabelecer suas próprias regras de acesso, de duração e, também, de preço.

A Universidade de São Paulo, por exemplo, sistematizou suas regras criando um programa de aprimoramento em pesquisa avançada, que é executado sob a supervisão de um pesquisador uspiano experiente não apenas em programas de pósgraduação stricto sensu, mas também em suas diversas unidades, museus e órgãos complementares. O objetivo parece muito claro: receber pesquisadores de fora da universidade (sejam nacionais ou estrangeiros) para executarem pesquisas e proporcionar trocas com o ambiente local, melhorando a excelência da universidade, inclusive com a previsão de que eles possam assumir orientações em programas de graduação e de pósgraduação. ${ }^{19}$

A ausência de bolsa não significa que o pesquisador que esteja desenvolvendo seu pós-doutorado na USP não tenha nenhum benefício. Ao revés. Esses pesquisadores poderão participar de atividades de capacitação e possuirão acesso a toda estrutura da universidade para o desenvolvimento de suas pesquisas, como, por exemplo, as bibliotecas, aos laboratórios e ao eduroam (rede de conectividade sem fio). ${ }^{20}$

19 Art. $6^{\circ}$ que alterou o art. 13-A do regulamento de pós-doutorado da USP. Ver em http://www.leginf.usp. br/?resolucao=resolucao-copq-no-7660-de-22-de-maio-de-2019. Acesso em: 7 fev. 2021.

20 A Pró-Reitoria da USP desenvolveu um guia sobre o seu Programa de Pós-Doutorado com todas as informações sobre requisitos e benefícios: https://prp.usp.br/wp-content/uploads/sites/649/2016/05/Guia- 
8. Pós-doutorado, produção e internacionalização dos programas de pós-graduação

Uma questão interessante que deve ser enfrentada é se o desenvolvimento de um pós-doutorado por um professor de programa de pós-graduação stricto sensu traz impacto para o programa em dois itens de avaliação, que é a produção científica e a internacionalização.

Um estudo realizado por Pedro Castro enfrentou alguns pontos interessantes, como, por exemplo, se há diferenças de produtividade entre docentes que fazem e que não fazem estágios pós-doutorais no Brasil ou no exterior; se o interstício entre a defesa da tese de doutorado e o ingresso no pós-doutorado interfere na produtividade acadêmica; se há alterações significativas de produtividade de pesquisadores de áreas diferentes e que realizaram estágios pós-doutorais; e se a realização do pós-doc interfere, ou não, no aumento da produção em revistas internacionais indexadas.

Segundo a pesquisa realizada, a experiência no exterior aumenta em 0,42 a produção científica. Porém, se o docente faz um doutorado pleno no exterior e um pósdoutorado no Brasil, a tendência é de queda de produção:

Os resultados vão na direção de mostrar que o par BrasilBrasil (doutorado no Brasil-pós-doutorado no Brasil), possui em média uma influência pífia sobre a produtividade docente (média de variação $=0,06$ ), praticamente não havendo diferença em termos gerais da produção, em decorrência da realização do estágio de pós-doutorado. No caso do par doutorado realizado no exterior aliado a um pós-doutorado realizado no Brasil, essa variação chega a ser negativa $(-0,13){ }^{21}$

Já com relação à pausa entre o doutorado e o pós-doutorado, quanto maior o tempo, maior a produção posterior. Isso, naturalmente, tem a ver com o grau de maturidade que alcança o pesquisador ao ter a experiência exógena do estágio pós-doutoral em uma instituição que não é a sua. Quanto às áreas de conhecimento, o autor apresenta dados que indicam a não comprovação da hipótese segundo a qual haveria desvios de produtividade significativos em razão de áreas mais produtivas (como ciências biológicas) em detrimento de outras. Quanto à produção em revistas indexadas internacionalmente, foi comprovado um aumento de $49 \%$ para 53\%, destacando-se o aumento em revistas indexadas Qualis A e, também, destacando-se que esse aumento de produção é relacionado aos pesquisadores

para-o-Programa-de-P\%C3\%B3s-Doutorado-da-USP.pdf. Acesso em: 31 jan. 2021.

21 CASTRO, Pedro Marcos Roma de. A influência dos Estágios Pós-Doutorais sobre a Produtividade Docente no Sistema de Pós-Graduação: o caso da USP. 2005. Dissertação (Mestrado em Administração) - Faculdade de Economia, Administração e Contabilidade, Universidade de São Paulo, São Paulo. p. 63. Disponível em: https://www.teses.usp.br/teses/disponiveis/12/12139/tde-22082006-154800/publico/ DissertacaoPedro.pdf. Acesso em: 7 fev. 2021. 
que realizaram seu pós-doutorado no exterior. Nesse sentido, o estágio pós-doutoral no exterior aumenta (embora pouco) a produção internacionalizada qualitativa.

Esses dados foram depois abordados por Marcello Calvosa ${ }^{22}$ em uma resenha que analisa o papel do pós-doutorado e o seu impacto no âmbito da pósgraduação. Não se pode deixar de considerar a relação íntima que o pós-doutorado possui com o sistema de mestrados e doutorados. As pesquisas evidenciam que a capacitação em pesquisa posterior à defesa do doutorado gera a maturidade do docente, com benefícios para a produção e a internacionalização do programa ao qual pertence.

\section{Conclusões}

O tema do pós-doutorado ainda é muito pouco estudado. A ausência de uma regulamentação geral que possa estabelecer diretrizes e conceitos mínimos favorece a desinformação sobre o que é efetivamente um pós-doutorado.

Com isso, questões como requisitos de acesso, duração, procedimento de apresentação de relatórios de pesquisa pós-doutorais e designação do docente que realiza um estágio pós-doutoral seguem em aberto, dependendo muito das regras adotadas pelas instituições de fomento e, também, pelas próprias instituições que recebem pesquisadores para o desenvolvimento de suas pesquisas pós-doutorais.

Com tantas dúvidas, algumas certezas: em primeiro lugar, de que não se trata de um curso integrante do sistema de pós-graduação. Ao contrário, é externo ao sistema. É um estágio de pesquisa. Em segundo lugar, que, apesar disso, o desenvolvimento do pós-doutorado pode ser um bom indicador para o fortalecimento do próprio sistema de pósgraduação, notadamente com o aumento de produção equalizada no plano internacional.

É justamente pelo pós-doutorado não ser integrante do sistema de pósgraduação stricto sensu (mestrados e doutorados) que acho particularmente difícil que a Capes, enquanto órgão central do sistema, venha a estabelecer regras que definam o que é o estágio pós-doutoral. Isso pode até vir a acontecer no futuro, mas apenas como forma de avaliação dos próprios programas nas avaliações quadrienais, ou seja, uma definição de critérios para aceitar computar, no corpo docente, professores que fizeram ou que não fizeram um pós-doutorado. Nessa parte, a regulamentação seria indireta, reflexa, motivada na avaliação do próprio programa de pós-graduação, e não do pós-doutorado.

22 CALVOSA, Marcello Vinicius Doria. (2019). Reflexões sobre a influência do pós-doutorado sobre produção científica da pós-graduação. Administração: Ensino e Pesquisa, 20(2), 537-544. https://doi. org/10.13058/raep.2019.v20n2.1352. Acesso em: 9 fev. 2021. 